\title{
Online Auction - A Study of Auction in Yahoo! Taiwan
}

\author{
Kun-Huang Huarng ${ }^{1}$ Hsin-Yi Cheng ${ }^{2}$ \\ ${ }^{1}$ Department of International Trade, Feng Chia University \\ ${ }^{2}$ Department of Business Administration, Feng Chia University \\ Email: khhuarng@fcu.edu.tw
}

\begin{abstract}
Shopping online has become more and more popular. Many people participate in online auctions. Due to the popularity of online auction, this study intends to study the possible factors that affect the transactions in online auction. This study uses the MP3 in the auction of Yahoo! Taiwan as the target and examines several factors that may affect the results. Using logistic regression and decision tree, this study successfully identifies the decisive factors and explores the relationship between these factors and the transaction results.
\end{abstract}

Keywords: decision tree, logistic regression, MP3, online auction.

\section{Introduction}

According to FIND (Focus on Internet News \& Data ${ }^{1}$ ) in Taiwan, the household connection to the Internet increases from $57 \%$ in 2003 to $61 \%$ in 2005 . The participants in online auction increase from $9 \%$ in 2003 to $14.8 \%$. Indeed, the Internet provides a good channel for auctions.

Auction started long ago. Various definitions have been rendered. Auction was considered as a mechanism for price competition between buyers and sellers (Bierman \& Fernandez, 1998). Auction was defined as a market for the participants to determine resource distribution and price under specific rules (McAfee \& MacMillan, 1987). Auction was also regarded as a resource distribution of scare resource and pricing mechanism under uncertain situations (Cramton, 1998). However, the purpose of an auction can be categorized into four aspects: a co-ordination mechanism, a social mechanism to determine a price,

\footnotetext{
${ }^{1}$ http://www.find.org.tw
}

an efficient allocation mechanism, and a highly visible distribution mechanism (Klein, 1997).

Two popular auctions are English auction, which bids up the price gradually and the highest bidder wins the auction, and Dutch auction, which bids down gradually and the lowest bidder wins the auction.

Online auction is considered as to match buyers and sellers and the auction web site is to provide a virtual space for transaction (Heck \& Ribbers, 1997). Reck (1997) considered online auction as using web to transmit information about products and services and sells the products and services via a bidding process.

To explore the transactions in online auction, this study uses some variables in previous studies to examine the auctions in Yahoo! Taiwan. Logistic regression and decision tree are used as analytic tools to identify decisive factors to affect transaction results.

\section{Data}

According to the survey of Insightxplorer in June $2003^{2}$, there are $62 \%$ web viewers ever browse auction websites; and there are $80.3 \%$ of them browsed the auctions in Yahoo! Taiwan and $40.9 \%$ ever browse eBay Taiwan. According to the news from Yahoo! Taiwan ${ }^{3}$, the total transaction amount was more than 10 billion New Taiwan (NT) dollars in 2003 and 16.4 billion NT in 2004. This study compares the auction items on the auctions in Yahoo! Taiwan ${ }^{4}$ and eBay ${ }^{5}$, Taiwan on October 1, 2005, the former had 6,616,629 items and the latter had 995,029 items. From either the transaction amount or the number of items, Yahoo! Taiwan seems superior to its counterpart. Hence, this study decides to pick Yahoo! Taiwan as our study case.

2

http://www.insightxplorer.com/news/news_07_24.htm

$\frac{1}{3}$

${ }^{3}$ http://tw.promo.yahoo.com/aboutcompany/

4 http://tw.bid.yahoo.com/

5 http://www.ebay.com.tw 
To be more specific, this study focuses on MP3. We further narrow the product to be with the specification of 512M because among all the MP3, 512M (2073 items) is of the largest amount in all various RAM specifications, including $128 \mathrm{M}, 256 \mathrm{M}$, $512 \mathrm{M}$, and $1 \mathrm{G}$.

\section{Methodology}

\subsection{Variables}

This study applies several variables, which are considered impacting the prices of products, including seller's rating (SR), photo $(\mathrm{Ph})$, shipping and handling (S\&P), bidding range (BR), product condition (PC), start price (SP), weekend effect (WE), and buy price (BP).

Some studies considered that consumers can only rely on sellers' reputation to judge the quality of products in purchasing (Landon and Smith, 1998 \& Wood, Fan and Tan, 2002). The improvement of reputation can raise sales (Yamagishi and Matsuda, 2003). We consider that the negative reputation will impact the overall reputation greatly. Hence, we use ratio to represent the reputation.

$\mathrm{SR}=$ seller's negative rating / seller's positive rating

A picture can paint thousand words. Photos are believed to provide more detail of products (Melnik and Alm, 2002). Online auctions with photos tend to have higher ending prices (Wood and Kauffman, 2001). Hence, when the product is with photo, we assign 1 to the variable photo, otherwise 0 .

We also assign 1 to the variable shipping \& handling if seller pays the fee, and otherwise 0 . Instead of waiting for the increment of bidding price, the seller can set the buy price. In this case, we set the variable buy price to 1 , otherwise 0 . Auction is considered attractive because of the bidding process. Hence, the range of price competition is considered to be included. If there is no buy price or the buy price is greater than the start price, we set the range of price competition to 1 , otherwise 0 .

Quality is also a factor to be included. If the product is of brand new, the variable quality is set to 1 , otherwise 0. Start price is another factor. Some study considered the higher the start price, the lower the motivation the buyer (Lucking-Reiley, 2000). Some study even pointed out the low start price is one of the ways to stimulate the competition (Staw, 1981; Malhotra and Murninghan, 2001).
Some studies believed that to end the auction on weekends may attract more competitions because more people are free to join (Lucking-Reiley et al., 2000). If the auction ends on weekend, the variable is set to 1 , otherwise 0 .

\subsection{Tools}

This study applies logistic regression and decision tree to analyze how relevant variables affect the auction results. The software we use is SPSS Clementine 7.2.

\section{Empirical Analysis}

This study collects the data of MP3 players with 512M RAMs from the auctions in Yahoo! Taiwan. The duration is from October 1, 2005 to October 10, 2005. The reason for choosing 10 days is that the auctions in Yahoo! Taiwan allows only 10 days for auction. There are totally 1012 observations, including 259 successful and 753 failed transactions. We separate the observations into in-sample $(911,90 \%)$ and out-ofsample $(101,10 \%)$.

\subsection{Estimation}

First, we use the logistic regression and decision tree in SPSS Clementine 7.2 for empirical analysis. Using logistic regression, we obtain the following equation:

$$
\begin{aligned}
& {[\mathrm{Tr}=0]=(-1.494)+15.68 * \mathrm{SR}+0.0007505 * \mathrm{SP}+} \\
& \text { (.000) } \\
& (-0.7742) *[\mathrm{BP}=0]+0.7697 *[\mathrm{WE}=0] \\
& \text { (.013) (.000) }
\end{aligned}
$$

where [ $\mathrm{Tr}=0$ ] represents failed transaction; SR means seller's rating; SP means start price; $[\mathrm{BP}=0]$ represents no buy price; $[\mathrm{WE}=0]$ represents not in weekend.

Using equation (2), we can conduct the estimation. The results are shown in Table 1 . There are 649 failed transactions out of 679 estimated as failed; there are 52 out of 232 successful transactions estimated as successful. The percentage is $95.58 \%$ and $22.41 \%$, respectively. In other words, equation (2) is more suitable for identifying failed transactions than successful ones.

Table 1. Estimation by the Logistic Regression* 


\begin{tabular}{|c|c|c|c|}
\hline Actual $\backslash$ Estimated & 0 & 1 & $\%$ \\
\hline 0 & 649 & 30 & $95.58 \%$ \\
\hline 1 & 180 & 52 & $22.41 \%$ \\
\hline & & & $76.95 \%$ \\
\hline
\end{tabular}

* Note that 0 means failed transaction and 1 successful transaction, respectively. The same for the rest of Tables.

We also use the decision tree for analysis. The estimation results are shown in Table 2. There are 644 failed transactions out of 679 estimated as failed; there are 120 out of 232 successful transactions estimated as successful. The percentage is $94.85 \%$ and $51.72 \%$, respectively.

The estimation results from the decision tree also show that the decision tree is more suitable for identifying failed transactions than successful ones. However, the identification of successful ones is more than $50 \%$.

Table 2. Estimation by the Decision Tree

\begin{tabular}{|c|c|c|c|}
\hline Actual\Estimated & 0 & 1 & $\%$ \\
\hline 0 & 644 & 35 & $94.85 \%$ \\
\hline 1 & 112 & 120 & $51.72 \%$ \\
\hline & & & $83.86 \%$ \\
\hline
\end{tabular}

\subsection{Forecasting}

First, we use equation (2) for forecasting. The results are shown in Table 3. There are 72 failed transactions out of 74 forecast as failed transactions; there are 8 out of 27 successful transactions forecast as successful transactions. The percentage is $97.30 \%$ and $29.63 \%$, respectively. As in the estimation, the forecasting is more suitable for failed transactions than successful ones.

Table 3. Forecasting by the Logistic Regression

\begin{tabular}{|c|c|c|c|}
\hline Actual|Forecast & 0 & 1 & $\%$ \\
\hline 0 & 72 & 2 & $97.30 \%$ \\
\hline 1 & 19 & 8 & $29.63 \%$ \\
\hline & & & $79.21 \%$ \\
\hline
\end{tabular}

The forecasting results by the decision tree are listed in Table 4. There are 9 failed transactions out of 74 forecast as failed transactions; there are 9 out of 27 successful transactions forecast as successful transactions. The percentage is $87.84 \%$ and $33.33 \%$, respectively. As in the estimation, the decision tree is more suitable for forecasting the failed transactions than successful ones.

Comparing with these two tools, the Logistic regression performs better in forecasting failed transactions and in overall forecasting, while the decision tree performs better in forecasting successful transactions.

Table 4. Forecasting by the Decision Tree

\begin{tabular}{|c|c|c|c|}
\hline Actual|Forecast & 0 & 1 & $\%$ \\
\hline 0 & 65 & 9 & $87.84 \%$ \\
\hline 1 & 18 & 9 & $33.33 \%$ \\
\hline & & & $73.27 \%$ \\
\hline
\end{tabular}

\section{Conclusion}

This study intends to explore the variables that affect the transactions in online auction. Logistic regression and decision tree are applied. The data are the $512 \mathrm{M}$ MP3 from the auctions in Yahoo! Taiwan.

The forecasting results from both tools show that to forecast the failed transaction is much better than to forecast the successful transactions. Those variables that may result in the failed transactions in this study include seller's rating, start price, buy price, and weekend effect.

The results are contrary to many previous studies that rendered the finding about successful transactions. There are some possible reasons. One could be due to the sample data. Hence, the future study can apply other data, including different auction target, longer duration, etc.

Another possible reason can contribute to that it is easy to regulate the behaviors of failed transactions, but it is rather not that straightforward to formulate those of the successful ones. However, the results from this study still can be used to prevent failed transactions.

\section{References}


[1] Bierman, H. S. and L. Fernandez, "Game Theory with Economic Applications," Addison-Wesley, USA., 1998.

[2] Cramton, P., "Ascending Auction," European Economic Review, Vol. 24, 1998.

[3] Heck, E. V. and P. M. Ribbers, "Experiences with Electronic Auctions in the Dutch Flower Industry", Electronic Markets, Vol. 7, pp. 42934, 1997.

[4] Klein, S., "Introduction to Electronic Auctions," Electronic Markets, Vol. 7, No. 4,.pp. 3-6, 1997.

[5] Landon, S. and Smith, C. E. , "Quality Expectations, Reputation, and Price," Southern Economic Journal, Vol. 64(3), pp. 628-647, 1998.

[6] Lucking-Reiley, D., "Auctions on the Internet: What's Being Auctioned, and How?" Journal of Industrial Economics, Vol. 48, No. 3, pp.227252, 2000.

[7] Lucking-Reiley, D., Bryan, D., Prasad, N., and Reeves D., "Pennies from eBay: The Determinants of Price in Online Auctions," Working Paper, University of Vanderbilt., 2000.

[8] Malhotra, D., and Murninghan, J. K., "Milked for all their Worth: Competitive Arousal in the Chicago Cow Auctions," Working Paper, Kellogg Graduate School of Management, Northwestern university, 2001

[9] McAfee, R. P. and J. MacMillan,, "Auctions with Stochastic Number of Bidders," Journal of Economic Theory, Vol. 43, No.1, pp. 1-19, 1987.

[10] Melnik, M. and Alm, J., "Does a Seller's eCommerce Reputation Matter? Evidence from eBay Auctions," Journal of Industrial Economics, pp. 337-349, 2002.

[11] Reck, M., "Trading-Process Characteristics of Electronic Auctions," Electronic Markets, Vol. 7, No. 4, pp. 17-23, 1997.

[12] Staw, B. M., "The Escalation of Commitment to a Course of Action," Academy of Management Review, Vol. 6, pp. 577-587, 1981.

[13] Wood C., Fan M. and Tan Y., "An Examination of Reputation Systems for Online Auctions," Working Paper, University of Washington., 2002.

[14] Wood, C. and Kauffman, R. J., "What Factors Drive Final Price in Internet Auctions? A MultiYear Assessment of Coin Transactions on eBay," Convention of the Institute for Operations Research and the Management Sciences, 2001.

[15] Yamagishi T. and Matsuda, M., "The Role of Reputation in Open and Closed Groups: An Experiment Study of Online Trading," Working Paper, 2003. 